Article

\title{
Expression of Interleukin-6 and the Interleukin-6 Receptor Predicts the Clinical Outcomes of Patients with Soft Tissue Sarcomas
}

\author{
Koichi Nakamura, Tomoki Nakamura *(D), Takahiro Iino, Tomohito Hagi, Kouji Kita, \\ Kunihiro Asanuma and Akihiro Sudo ${ }^{D}$
}

Department of Orthopaedic Surgery, Mie University Graduate School of Medicine, Tsu 514-8507, Japan; k-nakamura@clin.medic.mie-u.ac.jp (K.N.); tiino@clin.medic.mie-u.ac.jp (T.I.); hagifana@clin.medic.mie-u.ac.jp (T.H.); kkita@clin.medic.mie-u.ac.jp (K.K.); kasanum@clin.medic.mie-u.ac.jp (K.A.); a-sudou@clin.medic.mie-u.ac.jp (A.S.)

* Correspondence: tomoki66@clin.medic.mie-u.ac.jp; Tel.: +81-592315022

Received: 20 February 2020; Accepted: 2 March 2020; Published: 3 March 2020

\begin{abstract}
Interleukin-6 (IL-6) affects the key parameters of oncogenesis, which increases the cell resistance to apoptosis, the proliferation of cancer cells, angiogenesis, invasion, malignancy, and the ability of tumor cells to respond to anticancer therapy. This study aimed to elucidate the association between IL-6 and IL-6 receptor (IL-6R) expression in tissues and clinical outcomes in patients with soft tissue sarcomas (STSs) because, to our knowledge, this has not been done before. We enrolled 86 patients with histologically-proven localized STSs who underwent surgical resection. The cohort included 48 men and 38 women, with a mean age of 65.6 years. The mean follow-up duration was 40.5 months. The expression of IL-6 and IL-6R was immunohistochemically determined. We analyzed prognostic factors for overall survival (OS) and metastasis-free survival (MFS). High IL-6 expression was observed in $23.3 \%$ (20/86), high IL-6R expression in 44.2\% (38/86), and high expression of both in $16.3 \%(14 / 86)$ of patients. Multivariate analysis showed that a high expression of both IL-6 and IL-6R was a prognostic factor for OS and MFS. We found that this high expression indicated that the patient had a poor prognosis for OS and MFS.
\end{abstract}

Keywords: soft tissue sarcoma; interleukin-6; interleukin-6 receptor; tissue expression; prognosis

\section{Introduction}

The inflammatory microenvironment plays an important role in the development of cancer [1]. Interleukin-6 (IL-6) is an essential cytokine in the cytokine cascade involved in the generation and regulation of inflammation [2]. Serum IL-6 levels have been reported to be associated with the prognosis of and tolerance to chemotherapy in several types of cancer, as well as with early recurrence $[3,4]$. A previous study demonstrated that the presence of systemic inflammation was a prognostic factor for patients with soft tissue sarcomas (STSs) [5-7]. Moreover, elevated levels of serum IL-6 were identified as important factors for survival and event-free survival in patients with STSs $[2,4,8]$.

Previously, we reported a relationship between the levels of serum IL-6 and its diagnostic and prognostic value in patients with STSs [9]. Elevated serum IL-6 levels are a predictor of STSs, and C-reactive protein (CRP) levels are strongly correlated with serum IL-6 levels [9]. We suggested that the measurement of IL-6 levels may be a useful method for identifying patients who are at a high risk of STSs and tumor-related death [9].

In addition to serum inflammatory biomarkers, the expression of inflammatory cytokines produced by tumor cells has been found to be related to survival in several cancer types. IL-6 expression in tissues was significantly associated with a poor prognosis in patients with squamous cell carcinoma of 
the esophagus [10]. IL-6 expression in tissues was significantly associated with invasion depth and lymph node metastasis in colorectal cancer; it also correlated with several clinicopathological factors, such as TMN stage [11]. Furthermore, IL-6 receptor (IL-6R) expression has been reported in cancer cells. IL-6R expression in tissues has been reported to be significantly associated with invasion depth and lymph node metastasis in gastric cancer [12]. Moreover, IL-6R in tissues has been found to be a prognostic factor for survival in cervical cancer $[13,14]$.

However, to the best of our knowledge, no previous studies have evaluated the association between IL-6 and IL-6R expression in tissues and clinical outcomes in patients with STSs. Therefore, this was the aim of the present study.

\section{Results}

\subsection{Patient, Tumor, and Treatment Characteristics (Table 1)}

In total, 86 patients were included in the study. They were histologically classified as follows: well-differentiated liposarcoma $(n=22)$, undifferentiated pleomorphic sarcoma $(n=13)$, myxofibrosarcoma $(n=14)$, dedifferentiated liposarcoma $(n=14)$, leiomyosarcoma $(n=9)$, malignant peripheral nerve sheath tumor $(n=3)$, myxoid liposarcoma $(n=3)$, synovial sarcoma $(n=4)$, and other high-grade sarcomas $(n=4)$.

According to the French Federation of Cancer Centers Sarcoma Group (FNCLCC) histological grading system, 25 STSs were grade 1, 27 were grade 2, and 34 were grade 3 . All patients underwent surgical tumor resection. Adjuvant radiotherapy was performed in 21 patients. Adjuvant or neoadjuvant chemotherapy was administered to 19 patients. Of 19 patients, 12 patients received neo-adjuvant chemotherapy.

Table 1. The demographics of the 86 patients with soft tissue sarcoma.

\begin{tabular}{ccc}
\hline Age & Mean (years) & $\mathbf{6 5 . 6}$ \\
\hline \multirow{2}{*}{ Gender } & Range & $10-88$ \\
& Male $(n)$ & 48 \\
& Female $(n)$ & 38 \\
\hline \multirow{2}{*}{ Tumor depth } & Superficial $(n)$ & 13 \\
& deep $(n)$ & 73 \\
\hline Tumor size & Mean $(\mathrm{cm})$ & 11.1 \\
\hline \multirow{2}{*}{ Grade } & High grade $(n)$ & 61 \\
& Low grade $(n)$ & 25 \\
\hline Serum IL-6 level & Mean $(\mathrm{pg} / \mathrm{mL})$ & 30.6 \\
\hline \multicolumn{2}{c}{ IL-6; Interleukin-6. }
\end{tabular}

\subsection{Expression of IL-6 and IL-6R in the Tumor Tissues of Patients with STSs}

A high expression of IL-6 was observed in $23.3 \%$ (20/86) of cases; thus, a low expression was observed in 76.7\% (66/86). The patients exhibiting a high expression of IL-6 were significantly older than those exhibiting a low expression $(p=0.03)$. Of the 61 patients with high-grade STSs, a high expression of IL-6 was observed in 29.5\% (18/61), while a high expression of IL-6 was observed in $8.0 \%$ $(2 / 25)$ of patients with low-grade STSs $(p=0.047)$. The mean serum IL-6 level was $90.3 \mathrm{pg} / \mathrm{mL}$ (median $31.6 \mathrm{pg} / \mathrm{mL}$ ) in patients with STSs exhibiting high IL-6 expression and $12.5 \mathrm{pg} / \mathrm{mL}$ (median $5.3 \mathrm{pg} / \mathrm{mL}$ ) in patients with STSs exhibiting low IL-6 expression $(p=0.001)$.

A high expression of IL-6R was observed in 44.2\% (38/86) of patients, whereas a low expression was observed in 55.8\% (48/86). There were no differences in patient age between those exhibiting a high or low expression of IL-6R $(p=0.98)$. A high expression of IL-6R was observed in 54.1\% (33/61) of patients with high-grade STSs and in $20.0 \%(5 / 25)$ of those with low-grade STSs $(p=0.004)$. The mean 
IL-6 level was $38.9 \mathrm{pg} / \mathrm{mL}$ (median $9.17 \mathrm{pg} / \mathrm{mL}$ ) in patients exhibiting a high expression of IL-6R and $24.0 \mathrm{pg} / \mathrm{mL}$ (median $6.10 \mathrm{pg} / \mathrm{mL}$ ) in those exhibiting a low expression $(p=0.36)$.

A high expression of both IL-6 and IL-6R in tissues was observed in $16.3 \%(14 / 86)$ of patients. Tumor grade, serum CRP, and IL-6 levels in patients exhibiting a high expression of both IL-6 and IL-6R were high (Table 2).

Table 2. Clinicopathological data of soft tissue sarcoma (STS) patients classified by IL-6 and IL-6R expression in tissues.

\begin{tabular}{|c|c|c|c|c|c|}
\hline \multicolumn{2}{|c|}{ Variables } & $\begin{array}{c}\operatorname{IL6}(+), \operatorname{IL6R}(+) \\
n=14\end{array}$ & $\begin{array}{c}\operatorname{IL6}(+), \operatorname{IL6R(-)} \\
\text { or IL6(-), IL6R(+) } \\
\qquad n=30\end{array}$ & $\begin{array}{c}\operatorname{IL6}(-), \operatorname{IL6R}(-) \\
n=42\end{array}$ & $p$ Value \\
\hline \multirow{2}{*}{ Age } & Mean (years) & 71.1 & 64.5 & 64.5 & 0.30 \\
\hline & Median (years) & 72.5 & 66.5 & 67.5 & \\
\hline \multirow{2}{*}{ Sex } & Male (n) & 4 & 18 & 26 & \multirow{2}{*}{0.17} \\
\hline & Female $(n)$ & 10 & 12 & 16 & \\
\hline \multirow{2}{*}{ Depth } & Superficial & 2 & 5 & 6 & \multirow{2}{*}{0.58} \\
\hline & deep $(n)$ & 12 & 25 & 36 & \\
\hline \multirow{3}{*}{ Size } & $\leq 10(\mathrm{~cm})$ & 7 & 21 & 20 & \multirow{2}{*}{0.29} \\
\hline & $>10(\mathrm{~cm})$ & 7 & 9 & 22 & \\
\hline & Mean $(\mathrm{cm})$ & 11.9 & 9.48 & 12.1 & 0.23 \\
\hline \multirow{2}{*}{ Grade } & High grade $(n)$ & 13 & 25 & 23 & \multirow{2}{*}{0.012} \\
\hline & Low grade $(n)$ & 1 & 5 & 19 & \\
\hline CRP level & Mean (mg/dL) & 5.3 & 0.40 & 0.88 & 0.000002 \\
\hline \multirow{2}{*}{ Serum IL-6 level } & Mean (pg/mL) & 87.7 & 27.6 & 13.7 & \multirow[t]{2}{*}{0.0039} \\
\hline & Median (pg/mL) & 71.5 & 5.65 & 5.73 & \\
\hline
\end{tabular}

IL-6; Interleukin-6, IL-6R; Interleukin-6 receptor, (+); high expression, and (-); low expression.

\subsection{Overall Survival (OS), Metastasis-Free Survival (MFS), and Prognostic Factors}

As of August 2019, 45 of the 86 patients had a continuous disease-free status, 6 had no evidence of disease, 10 were alive with the disease, 20 had died of the disease, and 5 had died of other causes. The five-year OS rate was $66.1 \%$ (95\% CI: 51.5-77.2\%). The five-year MFS rate was $59.8 \%$ (95\% CI: 46.9-70.6\%).

Patients exhibiting high IL-6 expression in tissues had poorer OS results than those exhibiting low expression. The OS at 5 years in patients exhibiting a high and low expression of IL-6 was $48.7 \%$ (95\% CI: $25.7-68.4 \%)$ and $72.0 \%$ (95\% CI: 52.6-84.5\%), respectively ( $p=0.01)$. The MFS at 5 years in patients exhibiting a high and low expression of IL-6 was 40.0\% (95\% CI: $19.3-60.0 \%$ ) and $65.2 \%$ (95\% CI: 48.7-77.5\%), respectively $(p<0.01)$. Next, we examined the OS, MFS, and prognostic factors of patients exhibiting a high and low expression of IL-6R. The OS at 5 years in patients exhibiting a high and low expression of IL-6R was 57.2\% (95\% CI: 37.2-72.9\%) and 74.7\% (95\% CI: 52.9-87.5\%), respectively $(p=0.03)$. The MFS at 5 years in patients exhibiting a high and low expression of IL-6R was $40.7 \%$ (95\% CI: $23.6-57.2 \%)$ and $77.0 \%$ (95\% CI: 59.8-87.5\%), respectively $(p<0.001)$.

Finally, we divided the 86 patients into three groups according to the expression of IL-6 and IL-6R in the tissues: (a) high expression of both IL-6 and IL-6R, (b) high expression of IL-6 or IL-6R, and (c) low expression of both IL-6 and IL-6R. The OS at 5 years was $40.8 \%$ (95\% CI: $15.6-64.9 \%$ ) for patients exhibiting a high expression of both IL-6 and IL-6R, 65.6\% (95\% CI: 40.1-82.3\%) for patients exhibiting a high expression of either IL-6 or IL-6R, and 76.1\% (95\% CI: 50.0-89.8\%) for patients exhibiting a low expression of both IL-6 and IL-6R (Figure 1). 


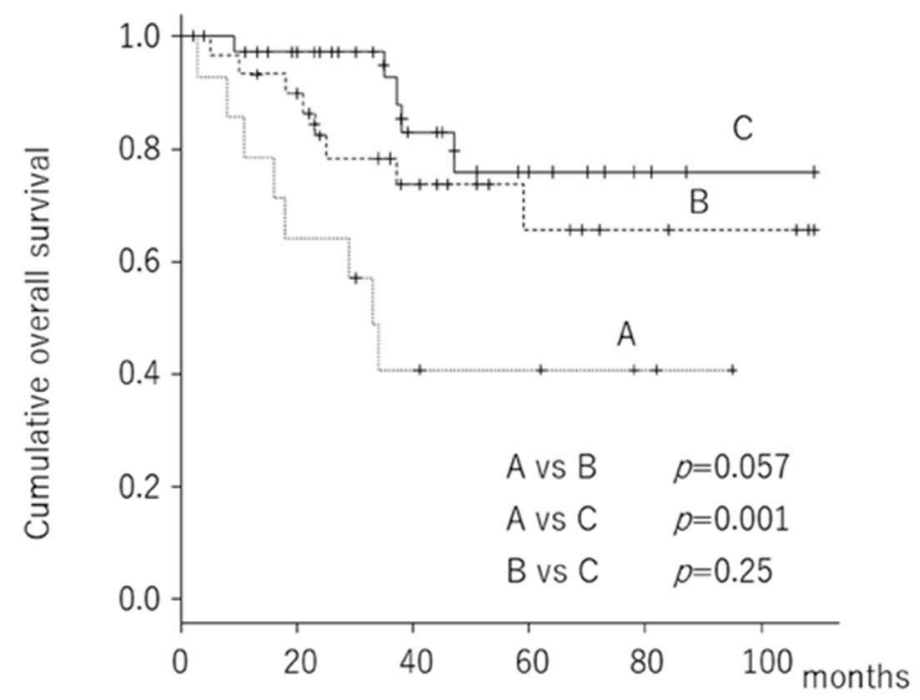

Figure 1. Kaplan-Meier curve showing overall survival according to the expression of IL-6 and IL-6R in the tumor tissue.

Univariate Cox hazard analysis revealed that a high expression of both IL-6 and IL-6R in tissues was a poorer prognostic factor for predicting OS than a low expression of both IL-6 and IL-6R. Age and tumor grade were also related to survival (Table 3). Upon multivariate Cox population hazard analysis, a high expression of both IL-6 and IL-6R in tissues and age remained prognostic factors for predicting OS (Table 4).

Table 3. Univariate cox population hazard analysis for overall survival and metastasis-free survival.

\begin{tabular}{|c|c|c|c|c|c|}
\hline \multirow{2}{*}{ Variables } & \multirow{2}{*}{ Parameters } & \multicolumn{2}{|c|}{ Overall Survival } & \multicolumn{2}{|c|}{ Metastasis-Free Survival } \\
\hline & & HR $(95 \%$ CI) & $p$ Value & HR (95\% CI) & $p$ Value \\
\hline Age & Years & $\begin{array}{c}1.073 \\
(1.023-1.125)\end{array}$ & 0.004 & $\begin{array}{c}1.033 \\
(1.001-1.066)\end{array}$ & 0.046 \\
\hline \multirow[t]{2}{*}{ Depth } & Superficial & 1 & & 1 & \\
\hline & Deep & $\begin{array}{c}1.941 \\
(0.451-8.363)\end{array}$ & 0.37 & $\begin{array}{c}1.297 \\
(0.454-3.71)\end{array}$ & 0.63 \\
\hline \multirow[t]{2}{*}{ Size } & $\leq 10 \mathrm{~cm}$ & 1 & & 1 & \\
\hline & $>10 \mathrm{~cm}$ & $\begin{array}{c}1.028 \\
(0.967-1.094)\end{array}$ & 0.37 & $\begin{array}{c}0.982 \\
(0.930-1.037)\end{array}$ & 0.52 \\
\hline \multirow[t]{2}{*}{ Grade } & Low grade & 1 & & 1 & \\
\hline & High grade & $\begin{array}{c}8.682 \\
(1.165-64.71)\end{array}$ & 0.03 & $\begin{array}{c}356200000 \\
\text { (0-Inf) }\end{array}$ & 0.99 \\
\hline \multirow[t]{3}{*}{$\begin{array}{l}\text { IL6 and IL6R } \\
\text { in tissues }\end{array}$} & IL6(+), IL6R(+) & $\begin{array}{c}5.124 \\
(1.673-15.69)\end{array}$ & 0.004 & $\begin{array}{c}6.780 \\
(2.616-17.57)\end{array}$ & 0.00008 \\
\hline & $\begin{array}{l}\text { IL6(+), IL6R(-), or } \\
\text { IL6(-), IL6R(+) }\end{array}$ & $\begin{array}{c}1.955 \\
(0.639-5.98)\end{array}$ & 0.24 & $\begin{array}{c}2.742 \\
(1.092-6.886)\end{array}$ & 0.03 \\
\hline & IL6(-), IL6R(-) & 1 & & 1 & \\
\hline
\end{tabular}

95\% CI; 95\% confidential interval, HR; hazard ratio, IL-6; Interleukin-6, IL-6R; Interleukin-6 receptor, (+); high expression, and (-); low expression. 
Table 4. Multivariate cox population hazard analysis for overall survival.

\begin{tabular}{ccc}
\hline \multirow{2}{*}{ Variables } & \multicolumn{2}{c}{ Overall Survival } \\
\cline { 2 - 3 } & HR (95\% CI) & $p$ Value \\
\hline Age & $1.064(1.016-1.115)$ & 0.009 \\
\hline $\begin{array}{c}\text { Grade high } \\
\text { Low }\end{array}$ & $\begin{array}{c}\text { (.955 (0.634-38.72) } \\
\text { IL6(+), IL6R(+) }\end{array}$ & 0.13 \\
\hline IL6(+), IL6R(-) or IL6(-), IL6R(+) & $3.537(1.125-11.12)$ & 0.03 \\
\hline IL6(-), IL6R(-) & $1.764(0.559-5.569)$ & 0.33 \\
\hline
\end{tabular}

95\% CI; 95\% confidential interval, HR; hazard ratio, IL-6; Interleukin-6, IL-6R; Interleukin-6 receptor, (+); high expression, and (-); low expression.

Patients exhibiting a high expression of both IL- 6 and IL-6R had poor MFS. The MFS at 5 years was $28.6 \%$ (95\% CI: 8.8-52.4\%) for patients exhibiting a high expression of both IL-6 and IL-6R, 52\% (95\% CI: 30.6-69.7\%) for patients exhibiting a high expression of either IL-6 or IL-6R, and 78.2\% (95\% CI: 58.6-89.3\%) for patients exhibiting a low expression of both IL-6 and IL-6R (Figure 2).

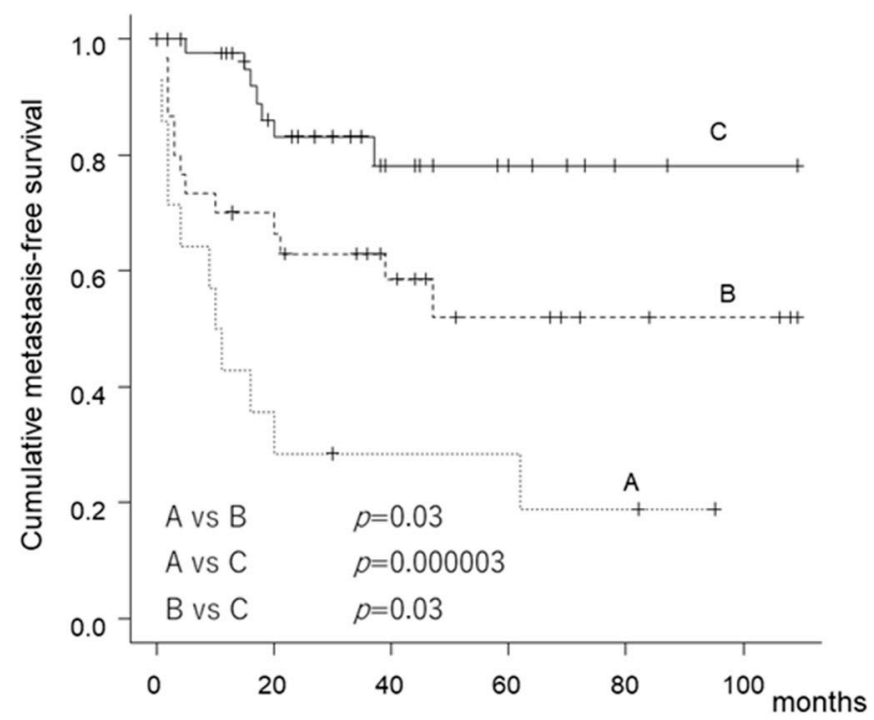

Figure 2. Kaplan-Meier curve showing metastasis-free survival according to the expression of IL-6 and IL-6R in the tumor tissue.

Univariate Cox hazard analysis revealed that patients exhibiting a high expression of both IL-6 and IL-6R had poorer MFS than those exhibiting a low expression. Patients exhibiting a high expression of either IL-6 or IL-6R in tissues had poorer MFS than those exhibiting a low expression (Table 3). Age was also a prognostic factor for predicting MFS. With regard to the multivariate analysis, a high expression of both IL-6 and IL-6R, a high expression of either IL-6 or IL-6R, and age were prognostic factors for predicting MFS (Table 5). Finally, we statistically validated the power of the study. The power for OS and MFS was $86 \%$ and $99 \%$, respectively. 
Table 5. Multivariate cox population hazard analysis for metastasis-free survival.

\begin{tabular}{ccc}
\hline \multirow{2}{*}{ Variables } & \multicolumn{2}{c}{ Metastasis-Free Survival } \\
\cline { 2 - 3 } & HR (95\% CI) & $p$ Value \\
\hline Age & $1.030(0.998-1.064)$ & 0.07 \\
IL6(+), IL6R(+) & $6.219(2.389-16.19)$ & 0.0002 \\
IL6(+), IL6R(-) or IL6(-), IL6R(+) & $2.909(1.153-7.340)$ & 0.02 \\
IL6(-), IL6R(-) & 1 & \\
\hline
\end{tabular}

95\% CI; 95\% confidential interval, HR; hazard ratio, IL-6; Interleukin-6, IL-6R; Interleukin-6 receptor, (+); high expression, and (-); low expression.

\section{Discussion}

IL-6 has pleiotropic effects on various cell types in the tumor microenvironment, which leads to the regulation of pro-oncogenic transcription factors NF- $\mathrm{kB}$ and STAT3 $[15,16]$. IL-6 affects the key parameters of oncogenesis, which increases cell resistance to apoptosis, the proliferation of cancer cells, angiogenesis, invasion, malignancy, and the ability of tumor cells to respond to anticancer therapies [15]. Serum IL-6 levels have been reported to be associated with the prognosis of several tumors. A systematic review reported that serum IL-6 levels were increased in the majority of clinical cancer studies, with a significant correlation between serum IL-6 levels and survival being documented in $86 \%$ of patients in 23 different cancer types [2].

In the present study, we showed the relationship between the expression of IL-6 and IL-6R in tissues and survival and MFS in patients with STSs. We also demonstrated the relationship between serum IL- 6 and CRP levels and the expression of IL- 6 in tissues. Kinoshita et al. reported that the levels of IL-6 in the serum reflected the levels in the tumor component [4]. Autocrine loops of IL-6 and IL-6R exist in several tumors [16,17]. IL-6 was found to be secreted by renal cancer cells to act as an autocrine tumor growth factor to induce the transcriptional inflammatory response and promote tumor progression through the JAK-STAT pathway [18]. Although there have been many studies on the relationship between serum IL- 6 and clinical outcomes in various cancers, there have been few studies investigating the relationship between IL-6 and IL-6R in tissues and clinical outcomes.

In the present study, we showed that a high expression of both IL-6 and IL-6R in tissues was related to MFS and OS in patients with STSs. Fu et al. reported that the positive expression of IL-6 and IL-6R in renal cell cancer was significantly associated with poor survival in multivariate analysis [19]. They also found that patients with a positive expression of both IL-6 and IL-6R had shorter cancer-specific survival than other groups (IL-6 negative/IL-6R positive, IL-6 positive/IL-6R negative, and IL-6 negative/IL-6R negative); these results support those of the present study. Interestingly, we found that patients exhibiting a high expression of either IL-6 or IL-6R had poorer MFS than those exhibiting a low expression of both IL-6 and IL-6R. Labovsky et al. reported that the expression of IL-6R in spindle stromal cells, such as carcinoma-associated fibroblasts and mesenchymal stem cells, was associated with disease-free survival (MFS) in patients with early breast cancer. Although we did not investigate these factors, tumor circumstance and cells may have affected the IL-6 pathway [20]. IL-6 and IL-6R may be potential therapeutic targets. The monoclonal anti-IL-6 antibody siltuximab showed anti-tumor effects against prostate cancer, renal cell cancer, and multiple myeloma [21]. The clinical trials using humanized anti-IL6R antibody tocilizumab are also approved for the on-label use of tocilizumab [21]. We believe that STS patients with a high expression of IL-6 and IL-6R may also be potential candidates for those clinical trials because their prognosis may be poor.

There are several limitations in the present study, including the retrospective design and the inclusion of 12 patients who received neo-adjuvant chemotherapy. The response to neoadjuvant chemotherapy may have affected the expression of IL-6 and IL6R. No correction for multiple testing was performed. However, this study is the first, to our knowledge, to describe the relationship between IL-6 and IL-6R in tissues and clinical outcomes in patients with STSs. However, further studies are 
necessary to validate this. We also tried to quantify the IL-6 and IL-6R levels using real- time PCR, but the tumor sample was not large enough to evaluate them.

In conclusion, we found that patients exhibiting a high expression of both IL-6 and IL-6R in tissues had a poor OS and MFS prognosis. We believe that the IL-6 autocrine loop in patients with STSs may be associated with tumor progression.

\section{Materials and Methods}

\subsection{Patients and Methods}

The study was approved (No.2804) by the Ethics Committee of Mie University Hospital. Written informed consent was obtained from all patients. The design and procedures of the study were carried out in accordance with the principles of the Declaration of Helsinki.

In total, 86 patients with STSs who underwent surgical resection between December 2008 and December 2017 at Mie University Hospital were retrospectively reviewed. Although we also treated another 30 patients with STSs, they were excluded from the present study because of a lack of information or disagreement of the study. The cohort included 48 men and 38 women, with a mean age of 65.6 years (range 10-88 years) at first presentation (Table 1). The mean follow-up duration was 40.5 months (range 1-109 months). Twenty patients who presented with recurrent disease and/or metastasis and 27 patients who were referred for additional resection after a previous inadequate excision were excluded, respectively. Four patients with an obvious history of myocardial infarction or infectious disease were also excluded. Histopathological diagnosis and tumor grade, determined using the French Federation of Cancer Centers Sarcoma Group (FNCLCC) system [22], were reviewed in all patients and confirmed by independent pathologists. We classified FNCLCC Grade 1 tumors as low-grade and Grade 2 and 3 tumors as high-grade. Blood samples from all patients were obtained within 1 month before initial treatment. All blood samples were stored at $-80^{\circ} \mathrm{C}$ until analysis. Blood samples were centrifuged at $1000 \times g$ for $15 \mathrm{~min}$. The levels of IL-6 were measured using an R\&D Systems ${ }^{\mathrm{TM}}$ Quantikine ${ }^{\circledR}$ ELISA kit (R\&D System Inc., Minneapolis, MN, USA).

\subsection{Immunohistochemical Staining}

Tumor tissue sections were subjected to immunohistochemistry analysis. Tumor blocks were formalin-fixed, paraffin-embedded, and sliced into $4 \mu \mathrm{m}$-thick sections. These were deparaffinized in xylene and rehydrated using diminishing concentrations of ethanol $(100 \%, 95 \%, 85 \%$, and $75 \%)$. This was followed by subsequent incubation in $3 \% \mathrm{H}_{2} \mathrm{O}_{2}$ for $30 \mathrm{~min}$ in the dark at room temperature to eliminate endogenous peroxidase activity. Antigen retrieval was performed by heating the sections for $10 \mathrm{~min}$ in citrate buffer ( $\mathrm{pH}$ 6.0) using the autoclave sterilizer method. The sections were allowed to cool at room temperature for $60 \mathrm{~min}$ and then rinsed three times for $5 \mathrm{~min}$ with fresh PBS. Thereafter, the slides were preincubated with healthy bovine serum albumin diluted in PBS (pH 7.4) for 15 min at $37^{\circ} \mathrm{C}$ and then incubated overnight at room temperature with primary antibodies specific for IL-6 (rabbit anti-IL-6, dilution 1:30, Santa Cruz Biotechnology, Dallas, TX, USA) and IL-6R (rabbit anti-IL-6, dilution 1:30, Santa Cruz Biotechnology, Dallas, TX, USA). After three rinses in fresh PBS, the slides were incubated with horseradish peroxidase-coupled secondary antibody for $40 \mathrm{~min}$ at room temperature. Following three additional washes, all specimens were stained with 3,3'-diaminobenzidine (DAB, Dojindo Laboratories, Kumamoto, Japan) substrate. Finally, the sections were rinsed in distilled water and counterstained with Mayer's hematoxylin, according to the manufacturer's instructions.

\subsection{Evaluation of Immunohistochemical Staining}

All sections were assessed by two orthopedic surgeons and one professional technician for pathology (T.I), who were blinded to patient outcomes and all clinicopathologic data. The two orthopedic surgeons (T.N and K.A) are orthopedic oncologists who are officially certified by the Japanese Orthopaedic Association. Expression was assessed semi-quantitatively using two parameters: 
staining intensity and the percentage of stained tumor cells, as suggested in previous studies [11,14] (Figure 3a,b). The immunohistochemical staining intensity was rated as follows: 1 point, weak intensity; 2 points, intense. Density was rated as follows: 0 point, $0 ; 1$ point, 1-50\%; 2 points, 51-75\%; and 3 points, 76-100\% of positive tumor cells (Figure 3). The eventual score of each specimen was calculated by adding the intensity and density scores. The expression levels of IL-6 and IL-6R were determined as low expression (score $\leq 2$ ) and high expression (score $\geq 3$ ) because the power of the present study for OS and MFS was the highest.

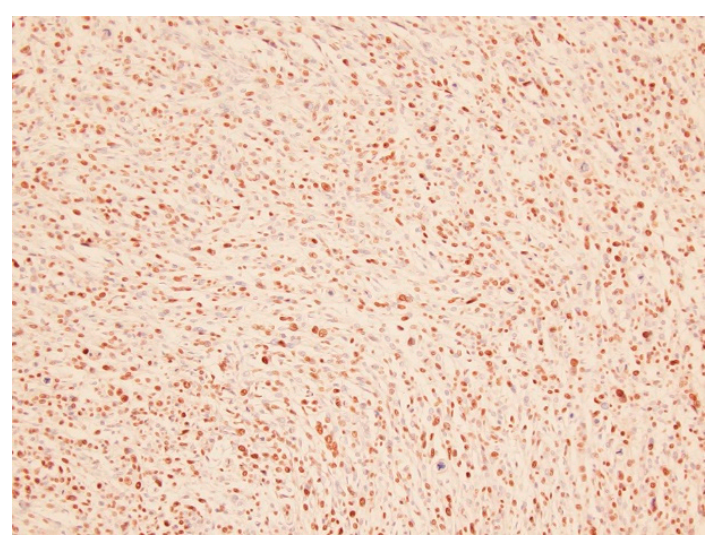

(a)

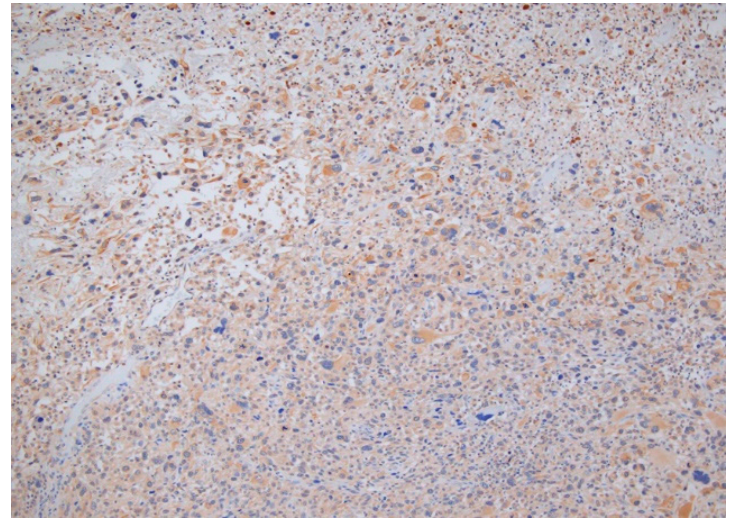

(b)

Figure 3. Immunohistochemical staining of IL-6 and IL-6R (a) Immunostaining for IL-6 $(\times 100)$. High expression of IL-6 in tumor tissue. (b) Immunostaining for IL-6R $(\times 100)$. High expression of IL-6R in the tumor tissue.

\subsection{Statistical Analysis}

Statistical associations between clinicopathological factors were evaluated using the Mann-Whitney U-test for quantitative data and the chi-squared test and Fisher's exact test for qualitative data. Correlations between IL-6 expression and/or IL-6R expression in tissues and clinical characteristics were tested using Spearman's rank-order correlation analysis.

Survival time was defined as the interval between the date of initial treatment for the primary tumor and the last date on which the patient was documented to be alive or the date of death. Survival curves were constructed using the Kaplan-Meier method. A log-rank test was used to compare the survival of patients exhibiting a high expression of IL-6 or IL-6R versus a low expression. Multivariate analysis was performed using a Cox proportional hazards model, including the significant predictors identified in the univariate analysis as variables. When we validated the power of the study, we defined the 0.05 of the alpha level. We calculated the power from the results of OS and MFS between the patients with both a high expression of IL-6 and IL-6R and those with both a low expression of IL-6 and IL-6R. The factors for multivariate analysis were selected by a stepwise method. A value of $p<0.05$ was considered significant. All statistical analyses were performed using the EZR graphical user interface (Saitama Medical Center, Jichi Medical University, Saitama, Japan) for R (the R Foundation for Statistical Computing, Vienna, Austria), which is a modified version of R Commander designed to add statistical functions frequently used in biostatistics.

\section{Conclusions}

This study aimed to elucidate the association between IL-6 and IL-6 receptor (IL-6R) expression in tissues and clinical outcomes in patients with STSs. We found that this high expression indicated that the patient had a poor prognosis for OS and MFS.

Author Contributions: Conceptualization, T.N.; methodology, T.N. and T.I.; software, K.N. and T.H.; validation, T.N. and A.S.; formal analysis, T.N.; investigation, T.N., K.N., K.K., T.H. and K.A.; resources, T.N., K.A. and T.H.; data curation, T.N., T.I. and K.A.; writing—original draft preparation, T.N. and K.N.; writing—review and editing, 
T.N. and A.S.; visualization, T.N.; project administration, T.N.; funding acquisition; A.S.; supervision, A.S. All authors have read and agreed to the published version of the manuscript.

Funding: This research received no external funding.

Conflicts of Interest: The authors declare no conflicts of interest.

\section{References}

1. Mantovani, A.; Allavena, P.; Sica, A.; Balkwill, F. Cancer-related inflammation. Nature 2008, 454, $436-444$. [CrossRef] [PubMed]

2. Lippitz, B.E.; Harris, R.A. Cytokine patterns in cancer patients: A review of the correlation between interleukin 6 and prognosis. Oncoimmunology 2016, 11, 5. [CrossRef] [PubMed]

3. Kita, H.; Shiraishi, Y.; Watanabe, K.; Suda, K.; Ohtsuka, K.; Koshiishi, Y.; Goya, T. Does postoperative serum interleukin-6 influence early recurrence after curative pulmonary resection of lung cancer? Ann. Thorac. Cardiovasc. Surg. 2011, 17, 454-460. [CrossRef] [PubMed]

4. De Vita, F.; Orditura, M.; Auriemma, A.; Infusino, S.; Roscigno, A.; Catalano, G. Serum levels of interleukin-6 as a prognostic factor in advanced non-small cell lung cancer. Oncol. Rep. 1998, 5, 649-652. [CrossRef]

5. Nakamura, T.; Grimer, R.J.; Gaston, C.L.; Watanuki, M.; Sudo, A.; Jeys, L. The prognostic value of the serum level of C-reactive protein for the survival of patients with a primary sarcoma of bone. Bone Joint J. 2013, 95, 411-418. [CrossRef]

6. Nakamura, T.; Matsumine, A.; Matsubara, T.; Asanuma, K.; Uchida, A.; Sudo, A. Clinical significance of pretreatment serum C-reactive protein level in soft tissue sarcoma. Cancer 2012, 118, 1055-1061. [CrossRef]

7. Szkandera, J.; Gerger, A.; Liegl-Atzwanger, B.; Absenger, G.; Stotz, M.; Samonigg, H.; Maurer-Ertl, W.; Stojakovic, T.; Ploner, F.; Leithner, A.; et al. Validation of the prognostic relevance of plasma C-reactive protein levels in soft-tissue sarcoma patients. Br. J. Cancer 2013, 109, 2316-2322. [CrossRef]

8. Rutkowski, P.; Kaminska, J.; Kowalska, M.; Ruka, W.; Steffen, J. Cytokine serum levels in soft tissue sarcoma patients: Correlations with clinico-pathological features and prognosis. Int. J. Cancer 2002, 100, $463-471$. [CrossRef]

9. Hagi, T.; Nakamura, T.; Iino, T.; Matsubara, T.; Asanuma, K.; Matsumine, A.; Sudo, A. The diagnostic and prognostic value of interleukin-6 in patients with soft tissue sarcomas. Sci. Rep. 2017, 7, 9640. [CrossRef]

10. Chen, M.F.; Chen, P.T.; Lu, M.S.; Lin, P.Y.; Chen, W.C.; Lee, K.D. IL-6 expression predicts treatment response and outcome in squamous cell carcinoma of the esophagus. Mol. Cancer 2013, 12, 26. [CrossRef]

11. Zeng, J.; Tang, Z.H.; Liu, S.; Guo, S.S. Clinicopathological significance of overexpression of interleukin-6 in colorectal cancer. World Gastroenterol. 2017, 23, 1780-1786. [CrossRef] [PubMed]

12. Simondurairaj, C.; Krishnakumar, R.; Sundaram, S.; Venkatraman, G. Interleukin-6 receptor (IL-6R) expression in human gastric carcinoma and its clinical significance. Cancer Investig. 2019, 37, 293-298. [CrossRef] [PubMed]

13. Zhijie, S.L.; Zhijie, A.; Bi, S.; Chen, L.; Fan, J. Interleukin 6 receptor (IL-6R) was an independent prognostic factor in cervical cancer. Histol. Histopathol. 2018, 33, 269-276.

14. Zeng, J.; Yang, X.; Cheng, L.; Liu, R.; Lei, Y.; Dong, D.; Li, F.; Lau, Q.C.; Deng, L.; Nice, E.C.; et al. Chemokine CXCL14 is associated with prognosis in patients with colorectal carcinoma after curative resection. J. Trans. Med. 2013, 11, 6. [CrossRef] [PubMed]

15. Dmitrieva, O.S.; Shilovskiy, I.P.; Khaitov, M.R.; Grivennikov, S.I. Interleukins 1 and 6 as main mediators of inflammation and cancer. Biochemistry 2016, 81, 80-90. [CrossRef] [PubMed]

16. Kawano, M.; Hirano, T.; Matsuda, T.; Taga, T.; Horii, Y.; Iwato, K.; Asaoku, H.; Tang, B.; Tanabe, O.; Tanaka, H.; et al. Autocrine generation and requirement of BSF-2/IL-6 for human multiple myelomas. Nature 1988, 332, 83-85. [CrossRef]

17. Okamoto, M.; Hattori, K.; Oyasu, R. Interleukin-6 functions as an autocrine growth factor in human bladder carcinoma cell lines in vitro. Int. J. Cancer 1997, 72, 149-154. [CrossRef]

18. Wolf, J.; Rose-John, S.; Garbers, C. Interleukin-6 and its receptors: A highly regulated and dynamic system. Cytokine 2014, 70, 11-20. [CrossRef]

19. Fu, Q.; Chang, Y.; An, H.; Fu, H.; Zhu, Y.; Xu, L.; Zhang, W.; Xu, J. Prognostic value of interleukin-6 and interleukin-6 receptor in organ-confined clear-cell renal cell carcinoma: A 5-year conditional cancer-specific survival analysis. Br. J. Cancer 2015, 113, 1581-1589. [CrossRef] 
20. Labovsky, V.; Martinez, L.M.; Calcagno, M.L.; Davies, K.M.; Garcia-Rivello, H.; Wernicke, A.; Feldman, L.; Giorello, M.B.; Matas, A.; Borzone, F.R.; et al. Interleukin-6 receptor in spindle-shaped stromal cells, a prognostic determinant of early breast cancer. Tumor Biol. 2016, 33, 13377-13384. [CrossRef]

21. Kang, S.; Tanaka, K.; Narazaki, M.; Kishimoto, T. Targeting Interleukin-6 Signaling in Clinic. Immunity 2019, 50, 1007-1023. [CrossRef] [PubMed]

22. Guillou, L.; Coindre, J.M.; Bonichou, F.; Nguyen, B.B.; Terrier, P.; Collin, F.; Vilain, M.O.; Mandard, A.M.; Le Doussal, V.; Leroux, A.; et al. Comparative study of the National Cancer Institute and French Federation of Cancer Centers Sarcoma Group grading systems in a population of 410 adult patients with soft tissue sarcoma. J. Clin. Oncol. 1997, 15, 350-362. [CrossRef] [PubMed]

(C) 2020 by the authors. Licensee MDPI, Basel, Switzerland. This article is an open access article distributed under the terms and conditions of the Creative Commons Attribution (CC BY) license (http://creativecommons.org/licenses/by/4.0/). 